\title{
Religião enquanto sentimento na obra inicial de Schleiermacher
}

Religion as feeling in the early work of Schleiermacher

\author{
Pedro Cortat ${ }^{1}$
}

\begin{abstract}
RESUMO: É a intenção deste trabalho apresentar, em caráter introdutório, a contribuição de Schleiermacher para o tema da religião no escopo comparativo da filosofia clássica Alemã. Especificamente, neste texto, de sua crítica e resposta a teologia moral de Kant. Isto é, sua redução da religião a um desdobramento da moral. Restringindo nossa análise aos conceitos e comentários do texto Sobre Religião: Discursos a Seus Menosprezadores Eruditos, essa resposta será formulada na apresentação da religião como intuição e sentimento do Universo. Ou seja, um caráter contemplativo, em vez de moral.
\end{abstract}

PALAVRAS-CHAVE: Religion, Schleiermacher, Feeling.

ABSTRACT: This paper aims to present, in an introductory manner, the contribution of Schleiermacher to the subject of religion in a comparative scope with classical German philosophy. Specifically, in this text, from his criticism and response to Kant's moral theology. That is, Kant's reduction of the religion to a unfolding of the moral. Restricting our analysis to the concepts and commentaries of the text On Religion: Discourses to its Scholarly Despiser. This answer will be formulated in the understanding of religion as intuition and feeling of the Universe. That is, a contemplative, rather than moral character.

KEYWORDS: Religion, Schleiermacher, Feeling.

\section{Introdução}

Schleiermacher ao longo de toda sua carreira atuou em diversos campos, dentre eles a teologia, filosofia e filologia. Desses aqueles sobre os quais mais escreveu foram os relacionados a teologia cristã e sua atividade de pregador (IZUZQUIZA, 1998) Entretanto, sua contribuição filosófica não fica diminuída, apesar de ser um autor pouco estudado, principalmente em língua portuguesa na filosofia. Contudo, nosso interesse neste texto não é discutir a relevância de sua obra de filosofia, mas sim apresentar um vislumbre de sua filosofia da religião, especificamente, também visando contribuir nessa direção.

Segundo indica Pannenberg não é necessário a nós dedicarmos muito tempo em tentar situar Schleiermacher como um filósofo, pois este "ocupa um lugar especial na história do idealismo alemão: ele foi o único teólogo que deu uma contribuição própria para o desenvolvimento da filosofia idealista" (2008, p 221 apud. OLIVEIRA, 2011, p. 10). Desse modo, só nos cabe estabelecer como se dá essa contribuição e como e com quem ela dialoga.

Schleiermacher é um filósofo moderno e está em diálogo com a história da filosofia anterior. A partir disso é preciso pontuar que "se a filosofia antiga havia tomado a realidade

\footnotetext{
${ }^{1}$ Mestrando em Filosofia na Universidade Federal de Juiz de Fora. Contato: pedro.cortat@ich.ufjf.br
} 
objetiva como ponto de partida de sua reflexão filosófica, e a medieval havia tomado a Deus como referência, a filosofia moderna se assentará no terreno da subjetividade" (FABERO, 2016, p. 55). Portanto, a contribuição deste no tocante da religião será na direção de considerar as religiões positivas como dadas, sem buscar deslegitimá-las, Deus enquanto o Universo, como referência da religião em essência, e por fim, aspectos da subjetividade na formatação dessa relação religião positiva, essência da religião.

A contribuição, a qual buscaremos desenvolver nas seções seguintes, busca antes de tudo reconhecer como bem sucedido esforço da filosofia moderna até em tão em negar à religião aderência metafísica, em segunda medida, ser crítico da solução Kantiana para o empasse do papel da religião. Isto é, que a religião, nas suas ideias de Deus, alma e liberdade é um desenvolvimento da moral.

Outra influência grande de Schleiermacher é o círculo romântico, o que acaba por ressaltar os dois conceitos principais de sua contribuição: religião enquanto sentimento e intuição do infinito. Nesse âmbito nosso autor busca desenvolver o aspecto da subjetividade, sem contudo cair em um subjetivismo, como buscaremos demonstrar. Nos é devido ressaltar que segundo Dreher "Schleiermacher tende a abandonar a ênfase na intuição" nas obras mais tardias (Dreher, 2004, p. 66). Contudo, nosso interesse aqui é desenvolver a apresentar a partir dos conceitos e comentadores do Über die Religion, e desse modo nos manter presos a obra inicial.

Isto significa considerá-lo enquanto parte do movimento romântico, e, portanto, considerá-lo como crítico do esclarecimento, sem contudo cair em um irracionalismo. Tanto este movimento quanto o idealismo em seus primeiros momentos, colocavam seus projetos filosóficos como projeto Kantianos em princípio. Ao acusar que pretendiam superá-lo não intencionavam negá-lo e retornar aos estudos pré-críticos. No entanto, pretendiam resolver lacunas ou discrepância, que, acusavam, ter sido deixadas por Kant. No caso específico de Schleiermacher, e nos limites desse trabalho, o papel da religião diante da moral (OLIVEIRA, 2011, p. 23)

Antes de adentramos na questão kantiana, e no desenvolvimento do pensamento de Schleiermacher buscaremos fazer um pequeno resumo do texto em questão, Über die Religion. Nele há uma "ênfase no caráter subjetivo e individual da religião, não obstante seu alcance universal e fundamental" (OLIVEIRA at al., 2010, p. 21), se o esclarecimento busca uma religião racional, negando a religião tal qual ela aparece no mundo, não é esse o procedimento neste texto, que buscará defender o papel da religião, sem negar a legitimidade de suas formas positivas. 
O texto abre com a defesa da autonomia da religião, em reação aos discursos iluministas que a desprezam. "Schleiermacher empenha-se, portanto, em tornar evidente a carência de um conceito suficiente de religião, capaz de dar conta de sua complexidade. Sua tese é de que a religião possui uma esfera própria de atuação: 'uma província própria no ânimo"” (OLIVEIRA, 2011b, p. 40). Isto é, que a religião não pode ser considerada como reunião de metafísica e de ética, mas como um campo autônomo.

O segundo aspecto mais importante, revidado dessa conclusão inicial, é que diferente de Kant a religião não é moral (já que o termo ética tem um escopo mais amplo na obra de Schleiermacher), ou antes dele metafísica, pois não é nem pensamento, nem ação, mas sim sentimento do infinito. Segundo ensina Dreher "ambiciona corrigir o que se diagnosticou como a unilateralidade do acesso proposto por I. Kant (1724-1804) à religião", veiculá-la a moral. Pois do ponto de vista de Schleiermacher "por mais promissora que fosse [esse desenvolvimento], e por mais que não se preste a leituras reducionistas, representou um 'estreitamento que não faz jus à dimensão do Absoluto' (DREHER, 2016, p. 6), o qual a religião busca contemplar (FABERO, 2016, p. 58) Estabelecida essa relação de crítica, nisso passamos a questão Kantiana, reiterando que tal crítica não é apenas negação.

\section{A leitura por Schleiermacher da religião em Kant}

Segundo alega Fabero nas três conhecidas interrogações kantianas resumem-se a metafísica, a moral, e a religião esta última sendo formulada como "o que posso esperar?". Entretanto, a resposta de Kant a questão final será de certo modo negativa, colocando sua resolução para dentro da resposta da segunda pergunta, "enquanto o sentimento religioso do homem concreto foi o cerne do pensamento de Schleiermacher" (FABERO, 2016, p. 58) sobre o assunto.

Para Kant “A moral conduz, pois, inevitavelmente à religião, pela qual se estende, fora do homem, à idéia de um legislador moral poderoso, cuja vontade é fim último (...) e ao mesmo tempo pode e deve ser o fim último do homem" (2008, p. 14). Esse procedimento é necessário, pois dentro de sua crítica Kant não pode fornecer uma prova ontológica ou cosmológica de Deus, mas apenas uma argumentação moral.

En el marco del uso teórico de la razón, Dios nos es dado, según el pensamiento kantiano, como un ideal trascendental, es decir, como un concepto de la razón pura teórico-especulativa, como un polo o principio regulativo hacia el cual avanza el conocimiento humano. La Idea por contener lo incondicionado (la totalidad de las 
condiciones de lo condicionado dado) sobrepasa el ámbito de toda experiencia posible, por lo que nunca podremos encontrar en la experiencia algo que le corresponda (lo perfecto o lo completo de una clase de cosa). En la Idea de Dios esta perfección puede ser tomada en dos sentidos, es decir, en un sentido teórico como ens summum, Dios (modelo de todo ente en cuanto tal), y en un sentido práctico como perfectio moralis (a lo que debería tender todo ente por obra de la libertad). Si bien, por medio de los conceptos trascendentales, según Kant, no se puede determinar ningún objeto, sin embargo, puede ser considerado imperceptiblemente, como el canon y la guía en el uso del entendimiento. (FABERO, 2016, p. 59)

Schleiermacher enquanto se coloca como continuador do projeto Kantiano não desejava negar essa limitação do conceito de Deus, que como ideal transcendental ultrapassa a experiência possível. “Antes, ele se limitou a descrever a relação com o Infinito ou 'Absoluto' como um fato ou dado experiencial da consciência do ser humano, ou seja, desde a finitude." (DREHER, 2004, p. 63-64) Desse modo está estabelecido em Schleiermacher, tal qual em Kant que não conhecemos Deus, mas diferente deste podemos aceitar que há "no dado da experiência religiosa propriamente compreendida, uma segurança de sua atuação sobre nós" (Idem).

Já em Kant os temas da da metafísica alma, mundo e Deus, “foram transferidos para o âmbito dos conceitos de razão (ideias), restritos à esfera dos princípios regulativos, cujo desdobramento posterior pertence ao âmbito da filosofia prática (KANT, 1974b)" (OLIVEIRA, 2016b, p. 124) É necessário, portanto, pensar a fé, como religião natural. "Esta reformulação kantiana pode ser descrita propriamente como uma 'teologia moral"” (Idem). Uma religião natural formulada a partir da razão pura prática.

Para Schleiermacher "na medida em que todas nossas convicções religiosas tem um caráter imediato, pertencem ao mais íntimo de nossa pessoa" (FABERO, 2016, p. 66) A ideia de produção de uma religião racional que se coloque como superação das religiões positivas é ilusória. “Assim, Schleiermacher fala da necessidade de descobrir nas 'religiões a religião', ou seja, é preciso buscar nas religiões aquilo que as torna religião, a saber, a presença do Infinito no finito" (OLIVEIRA, 2011, p. 156). Faz-se necessário, portanto, encarando as diversas manifestações na forma de religiões positivas, procurar seu elemento essencial.

Retomando para Schleiermachero não há nada de polêmico na crítica feita por Kant ao conhecimento metafísico, o autor assume todas as disposições da crítica kantiana no âmbito cognitivo. O problema para Schleiermacher é, portanto, a falta de autonomia da religião dentro desse sistema. 


\section{Metafísica, ética e religião como dimensões autônomas}

Tomamos como exemplo a leitura de Kant, feita por Schleiermacher, contudo é imperativo pontua que sua crítica é ampla e direcionada a posição do Esclarecimento, frente a religião. Desse modo, não só o erro de Kant, mas de todo o esclarecimento seria o de não compreender que "A metafísica, a moral e a religião são matérias que não se fundem entre si" (OLIVEIRA, 2016, p. 1570), são matérias imprescindíveis e dialogantes, mas não são a mesma coisa, ou redutíveis umas nas outras.

Ora, não só se tem confundido a religião com a metafísica e a moral, mas do mesmo modo tem-se mesclado a metafísica e a moral, o teórico e o prático entre si. Segundo Schleiermacher, a idéia do Bem, por exemplo, provém originariamente da moral, mas termina por adentrar na metafísica. Por seu turno, a idéia de um Ser primordial, que provém na verdade da metafísica, também invadiu o domínio da moral. (...) Schleiermacher não só defende a autonomia da religião, mas defende igualmente a autonomia da metafísica e da moral. A intenção de Schleiermacher é restituir a cada esfera particular sua própria especificidade. (OLIVEIRA, 2016, p. 1570)

Cada uma e todas essas esferas têm autonomia conceitual e metodológica, apesar das três fazerem referência ao mesmo objeto. O que segundo destaca Oliveira (2011b, p. 50) é a razão que levou os outros dois, metafísica e moral, a invadirem o domínio da religião. No caso da religião seu lugar não é nem volitivo, nem cognitivo, não é seu papel legislar sobre ações ou sistematizar conhecimentos. "Sua essência não é nem pensamento nem ação, mas sim intuição e sentimento" (Schleiermacher, 1970, p. 29 apud. OLIVEIRA, 2011, p. 143). Se por um lado a metafísica se relaciona com o Universo buscando conhecê-lo, e procurando deduzir nele suas causas finais, por outro a moral se relaciona procurando deduzir leis para determinar sua ação. A primeira é uma atividade teórica, pensar, a segunda é uma atividade prática, agir.

A religião, neste sentido, originalmente e, portanto, na sua essência, não busca nem o conhecimento da realidade, nem muito menos o aperfeiçoamento moral. O elemento essencial da religião para esse autor pertence à esfera do sentimento, i.e., assenta-se sobre um "dado experiencial fundamental da consciência do ser humano" (Dreher, 2004, p. 64), entendido como um modo de ser fundamental e íntimo de relação do homem com o Universo ou o Infinito. (OLIVEIRA at al., 2010, p. 22)

A moral e a metafísica buscam relacionar o infinito como finito no finito, o conhecimento metafísico é limitado pela nossa capacidade cognoscente, a determinação do 
cumprimento do é limitado pela não vontade e inclinações. Já a religião quer encontrar no finito, as religiões positivas, o sentimento originário da religião, o Infinito, aquilo que é sentido. "O órgão dos primeiros é o entendimento e a razão, seu papel é explicar e analisar trata-se de uma explicação científica. O órgão do último é o sentido, sua função é a intuição não se trata de explicar, mas de sentir" (OLIVEIRA at al., 2010, p. 22).

Por isso é necessário reiterar a crítica a moral Kantiana, a religião não serve com o móvel moral para Schleiermacher, pois religião é recepção. A "ação propriamente dita deve e também pode ser moral; porém, os sentimentos religiosos devem acompanhar todo o fazer do homem como uma música sagrada; ele deve fazer tudo com religião, mas nada a partir da religião" (Schleiermacher, 1970, p. 38-39 apud. OLIVEIRA, 2011, p. 153). A religião acolhe a ação e coloca sob perspectiva em relação com essa infinitude, isto é, dá o sentido infinito aquilo que era resultado de operações finitas.

(...) antes uma experiência originária do que um mero fato ou conjunto de fatos empíricos; antes algo próximo dos indivíduos e neles produtivo, inclusive por comunicação, do que algo neles inculcado por autoridade ou pressão social. (...) ela é primordialmente experiência e expressão que conhece os limites impostos pela alteridade, inclusive, mas não só, a religiosa. (...) As atividades do espírito como o pensar e o agir não se dão sem este pathos fundamental, que as ancora no infinito. (DREHER, 2016, p. 11)

O papel da religião é sentir o Universo, e desse modo oferecer um sentido para fora do finito. Se "tanto o pensar quanto o agir tomam para si a iniciativa em relação ao Universo, quer para forçá-lo a exprimir sua natureza, quer para forçá-lo a se conformar de acordo com nossa vontade" (OLIVEIRA, 2011b, p. 55), então a religião é passiva em relação a este e sua função é oferecer ao ser finito o gosto do infinito.

Schleiermacher afirma que "todo finito consiste apenas na determinação de seus limites que precisam ser como que recortados a partir do Infinito" (1970, p. 30 apud. Idem) Desse modo a religião tem o papel de oferecer ao ser humano um modo de sentir na Universo um todo e não partes de seu conhecimento, ou causas e consequência sobre as quais atua sua vontade simplesmente. Todo para Schleiermacher é pensado como orgânico, no qual as partes só fazem sentido em relação ao todo e o todo só aparece quando olhamos as suas partes. "A partir deste aspecto fica claro o papel que a religião desempenha, a saber, o de conter os avanços de uma subjetividade que pensa poder ser seu próprio fundamento último" (OLIVEIRA, 2011b, p. 55-56), seja na fundamentação de moral, como vimos em Kant ou da metafísica, como seria possível pontuar em Fichte. 


\section{A religião nas religiões}

Mencionamos o entendimento de Schleiermacher sobre todo e organismo, vale agora ilustrá-lo em seu tratamento das religiões positivas. Se ele busca estabelecer a essência da religião como Sentimento e Intuição do Infinito, deixará claro que só poderá encontrar essa essência enquanto olha para as traduções dessas intuições originárias na forma de religiões de fato. Cada religião, finita, é resultado de uma atividade infinita, na medida que este infinito é aquilo que é sentido pelo religioso em sua experiência religiosa e que é por ele traduzido, com a mediação de sua cultura e época. "Assim, todo o limitado apresenta-se como manifestação do Infinito, sendo que este não pode se manifestar senão no finito. E (...) todo e qualquer particular não pode ser descartado em favor de uma realidade universal e abstrata". (OLIVEIRA, 2011b, p. 58) Desse modo, como estudioso das religiões Schleiermacher é obrigado a considerar por um lado a necessidade de investigar a essência da religião, e por outro estudar a manifestação dessa essência como produto de um determinado lugar (cultural, temporal, histórico). Já que, como indica Oliveira (2016):

A manifestação da religião no interior do homem é a condição de possibilidade das religiões positivas ou históricas. A investigação deste lócus interno da religião marca o ponto de partida da pergunta pela essência da religião. Ao mesmo tempo, a condição concreta de manifestação desta essência supõe um caráter comunicativo e positivo, cuja efetivação se dá na forma das religiões históricas, sem as quais não haveria uma objetivação possível da natureza interior da religião. (OLIVEIRA, 2016, p. 1572)

Schleiermacher pode, a partir disso, afirmar que em essência religião é sentimento e gosto pelo infinito, mas não pode, simultaneamente, afirmar que esta ou aquela doutrina é em essência a religião como um todo. Enquanto religião positiva uma comunidade religiosa é tradução de uma intuição singular dessa essência, mediada por determinada época e cultura, mas não pode ser delimitada, uma vez que é antes de tudo particularidade, como aspecto fundamental desse todo.

Esse procedimento acaba por indicar uma relação tolerante do verdadeiro religioso, para com as diferentes manifestações religiosas. Como "não se pode conhecer o Infinito a 
partir das representações (que é a forma de conhecimento das coisas condicionadas), porque este tipo de saber é sempre mediado por elementos individuais. (...) pode-se ter acesso ao Infinito unicamente de forma imediata (sem representação) através de nosso contato com o finito” (OLIVEIRA, 2011, p. 25). Logo, só é possível aceitar a formulação religiosa própria e dos outros como forma imediata, e meios de contato pelo finito com esse infinito. Não sendo possível, nos termos de Schleiermacher, afirmar a supremacia de uma religião sobre as demais.

Cada Sagrada Escritura nada mais é do que um mausóleo, um monumento da religião que atesta que ali havia estado um grande espírito, mas que não há mais... Não tem religião quem crê em uma escritura, senão aquele que não precisa de uma e inclusive poderia ele mesmo produzir uma. (Schleiermacher, 1990, 79-80 apud. FABERO, 2016, p. 66)

Desse modo podemos inferir que ao sistematizar uma religião, o que causa intolerância é a confusão das partes da doutrina com aquilo que originou no doutrinador a necessidade de expressar aquela doutrina. "confundir o sistema com a realidade ultima ela mesma, nesse caso algo finito e condicionado, algo humano é tomado como absoluto" (MARINA, 2010, p. 11) Segundo indica Marina, para Schleiermacher essa idolatria é mesmo a causa da intolerância, enquanto aqueles realmente religiosos reconhecem "que Deus permanece sendo Deus, independentemente de quais ideias um ou outro tem de Deus. Deus não precisa ser defendido, o Absoluto não precisa ser atacado" (Idem), somente construtos humanos podem se prestar a esse tipo de ataque e comoção. Em outras palavras:

“"para mim, tudo é milagre” (1970, p. 66), pois é apenas um nome religioso para qualquer acontecimento, até o mais natural e habitual, que ressalta uma dada relação imediata com o Infinito. Uma vez que o homem religioso tende a ver em todo o finito e particular a presença do Infinito e do Todo, nada mais patente que a afirmação segundo a qual tudo que existe seja um milagre. (OLIVEIRA, 2011, p. 153)

A experiência religiosa não é a leitura da doutrina, ou a ação de caridade, mas é "aquele primeiro instante misterioso que ocorre com toda percepção sensível, antes ainda da intuição e do sentimento se separarem (...) (Schleiermacher, 1970, p. 41 apud. OLIVEIRA, 2011, p. 147). Nesse momento pré-cognitivo é quando a religião acontece, como sentimento, no qual é possível intuir o infinito. Justamente por esse caráter pré-reflexivo esse momento é "indescritível": 
Neste instante (Augenblick), as intuições e os sentimentos do Universo ainda se encontram intimamente conectados. À medida que este acontecimento se torna objeto de consideração e de reflexão, somente é possível descrever separadamente os produtos (intuição e sentimento) oriundos deste momento originário. Assim sendo, toda análise dissolve necessariamente a unidade desta experiência, e isso é inevitável, pois toda e qualquer tentativa de reconstrução deste instante é feita pela via da reflexão. Porém, a experiência considerada em seu momento de unidade revela uma comunhão entre o sentido e seu "objeto", em outras palavras, entre o homem e o Universo. (Idem)

As experiências religiosas por serem tão fugazes tem que ser compartilhadas, e é nessa necessidade que originam as religiões positivas. A experiência originária produz no indivíduo uma intuição do infinito, e quanto mais intenso for o sentimento que lhe é conjugado nesse momento, maior a vontade de "expressar e comunicar tudo o que está nele, e quanto mais violentamente algo o move, quanto mais internamente penetra seu ser, tanto mais forte atua também o impulso de contemplar, nos outros, a força do mesmo fora de si”" (SCHLEIERMACHER, 1970, p. 3 apud. OLIVEIRA, 2011, p. 154)

Para Schleiermacher as religiões são reflexos das diferentes vivências humanas, contudo elas não são um fenômeno humano puramente, já que a natureza transcendental da religião em essência aponta para algo além que fundamenta não só a própria religião, mas todas os demais desdobramentos da experiência humana. Isto significa, no que diz respeito as nossas tentativas de entender a religião que "enquanto disciplinas como a psicologia, sociologia e antropologia podem lançar luz na religião, esta não pode ser reduzida a um estudo dos objetos dessas disciplinas" (MARINA, 2010, p. 8). Aquilo que esses campos estudam, isto é "doutrinas religiosas, crenças, ritos praticados advém de reflexões condicionadas culturalmente, sobre esta experiência, o que é sempre uma reflexão de sujeitos finitos" não servindo para entender a religião em essência, mas apenas as religiões tal e qual elas aparecem historicamente.

Aquilo sobre o que versa a busca pela essência da religião desafia todas as nossas capacidades cognitivas, como fora postulado por Kant, e portanto, nossos conceitos dele ainda que sejam manifestação desse infinito no finito, para Schleiermacher, nunca se adéquam completamente a este (Idem, p. 9) Esclarecidos esses dois níveis de entendimento da religião, passaremos a última parte de nosso esforço dissecar melhor os dois conceitos que regem a experiência religiosa: sentimento e intuição.

\section{Religião enquanto sentimento e intuição}


A experiência religiosa é o momento onde a intuição do infinito e o sentimento do universo estão colocado como só uma coisa. Contudo, não é possível apresentá-lo unificadamente a reflexão, e a partir dali eles se tornam dois produtos, que por sua vez servirão de fundamentação das religiosidades particulares (OLIVEIRA, 2011b, p. 63). Desse modo, apesar da formulação kantiana, que:

"só permitia falar com rigor, (...) das esferas de validade teórica, prática e, (...) estética. Conforme esta lógica, o âmbito de realidade da religião, que mesmo em Kant vai confluir na ideia de Deus, depende ainda excessivamente de uma inferência, bem com de um juízo objetivamente infundado. (...) A subjetividade transcendental em Schleiermacher ultrapassa estipulações kantianas sem render-se a estratégias totais de revisionismo metafísico. (DREHER, 2016, p. 7)

Faz isso arrolando os conceitos de Sentimento e Intuição, que como destacado anteriormente, ressaltam um caráter não metafísico dessa experiência, mas buscam fornecer um meio de relação contemplativa entre o Infinito e o finito. Intuição não é um modo de conhecer, mas um modo de ser afetado pelo Universo:

"Todo intuir parte de um influxo do intuído sobre o que intui, de uma ação originária e independente do primeiro, que depois é assumida, recompilada e compreendida pelo segundo de uma forma acorde com sua natureza."; e p. 74 "Na religião é intuído o Universo, é concebido como atuando originariamente sobre o homem." (SCHLEIERMACHER, 2000 apud. DREHER, 2016, p. 8)

A intuição não fornece, portanto, o conhecimento do Infinito, isto seria uma metafísica pré-crítica. Através dela só é possível conseguir "uma imagem particular da ação do Universo sobre o homem" (OLIVEIRA, 2011, p. 153). Enquanto o sentimento "indica a intensidade com que esta ação específica atua sobre os sentidos" (Idem). Desse modo, a religiosidade positiva é manifestação finita do infinito, particularização, e não pode englobá-lo, mas ao sentir o infinito decorrer uma comoção para sua comunicação: "Por isso, quanto maior a sensibilidade e agudez dos sentidos, quanto mais ardente a sede e quanto mais irresistível o impulso de captar o Infinito, tanto mais perfeita e intensa será esta impressão do Universo, bem como tanto maior será a necessidade de expressá-lo" (Ibidem) e desse modo procurar um sentido infinito na ação finita. Pois enquanto a moral e a metafísica querem só podem colocar o homem como condição de todas as coisas "[a religião] quer ver no homem, não menos que em todo outro ser particular e finito, o Infinito, sua impressão, sua manifestação" (SCHLEIERMACHER apud. OLIVEIRA, 2011b, p. 54). 
Schleiermacher estipula diferentes modos de intuir o Universo, o que por sua vez ajuda na variedade da manifestação religiosa "pode-se intuir o Universo enquanto um caos, uma unidade sem qualquer distinção", que poderia ser o produtor de religiões animistas, "pode-se intuir o Universo enquanto uma pluralidade sem unidade ou uma multiplicidade indeterminada de elementos e forças heterogêneas", a intuição originária de religiões politeístas e "pode-se intuir o Universo enquanto totalidade, como uma unidade na pluralidade" como faria as religiões monoteístas. (SCHLEIERMACHER, 1970, p. 70-71 apud. OLIVEIRA, 2011, p. 158).

Apesar de não se tratar de um conceito do conhecimento, para Schleiermacher, a intuição se diferencia da sentimento na medida que a primeira pode ser entendida enquanto "olhar para fora em direção ao objeto, e sentimento como olhar para dentro, em direção ao centro da subjetividade" (Adams, 2005, p. 37). O primeiro tem um caráter teórico, que servirá a reflexão como parte do todo, e o segundo é uma autoconsciência imediata. Dessa maneira, é por isso que apesar desse caráter teórico, a intuição não é aqui conhecimento:

Todavia, a religião é infinita a partir de todos os lados, um infinito da matéria e da forma, isto é, a religião não só lida com o Infinito, mas há infinitas possibilidades de intuições do Universo (Schleiermacher, 1970, p. 35). Um sistema de intuições teria que necessariamente deixar alguma intuição de fora, a fim de evitar contradições internas. Porém, as intuições podem e devem viver lado a lado, ainda que cada uma seja totalmente diversa das outras. Este é o significado de individualidade. Cada intuição é una e, ao mesmo tempo, revela um aspecto do todo. (OLIVEIRA, 2011, p. 151)

Todas as intuições estavam na experiência religiosa unidas a um sentimento. Foi o desenvolvimento pela reflexão que as obrigou a se separar. Da mesma maneira que nossos órgãos produzem uma mudança interna advinda de objetos externos, tal qual operar intuição e o sentimento. O primeiro é a formulação do infinito no finito de uma manifestação particular sua, "toda intuição procede da influência do intuído naquele que intui, de uma ação original e independente do primeiro, que é então compreendida, apreendida e concebida pelo último, de acordo com sua própria natureza" (MARINA, 2010, p. 12). Enquanto o segundo é o meio deste alcançar a consciência do sujeito que intui, pois:

Se a luz - que acontece completamente sem nenhum esforço seu - não afetar seus sentidos, se nem as menores partes do seu corpo, as pontas dos teus dedos, se elas não forem mecânica ou quimicamente afetadas, se a pressão do peso não revelar a você uma oposição e um limite do seu próprio poder, você não intuiria e nem perceberia coisa alguma, e aquilo que você intui ou percebe não é a natureza das coisas, mas sua ação, sobre você. (Idem) 
Assim opera a religião, para Schleiermacher, sua parte intuitiva é o reconhecimento da presença do infinito, sua parte sentimental é o modo de recepção. O infinito provoca uma modificação da consciência finita, já que "toda e qualquer intuição vem acompanhada de sentimentos, (...) correspondem a uma alteração da consciência interna, pois conduzem o homem a uma nova relação com seu ânimo (Gemüt) e com sua condição (Zustand)" (OLIVEIRA, 2011b, p. 59).

Por fim, esses dois elementos entendidos separados são produtos da reflexão, que os separa, e se tornam portanto manifestação religiosa particular e vocação para fé, respectivamente. Enquanto, unidos, no momento de presença do infinito na consciência do finito, são eles os atributos que constituem a essência de religião para Schleiermacher.

\section{Considerações Finais}

Espera-se por meio deste trabalho ter-se alcançado os pontos levantados na introdução: pontuar a contribuição original de Schleiermacher ao tema da religião, mantendo restrita nossa análise aos conceitos e comentários do texto Sobre Religião: Discursos a Seus Menosprezadores Eruditos.

Enquanto a existência de uma causação metafísica, ou a descoberta de leis morais apontam para uma integração da realidade num todo tais postulações não são em si mesmas religiosas. Elas partes do finito e alcançam somete o finito, e se não fosse a intuição desse Universo, não seria possível alcançá-las para além de particularidades. Isto é só é possível compreender essas partes como duas partes de um todo, superar o dualismo teoria e prática, se já foi originário o sentimento do Universal, e não o contrário, buscando alcançá-lo simplesmente pela enumeração das partes.

Se Religião é nessa obra de juventude de Schleiermacher intuição e sentimento, ou "sentido e gosto pelo infinito" (DREHER, 2016, p. 11), ao invés de agir, como pressupõe a teologia moral de Kant, ou pensamento, como versava a metafísica pré-crítica. Então ela pode ser usada em conjunto com pensamento e ação, pois enquanto nesses termos, sentido e gosto pelo infinito, "ela é a fonte a partir da qual pensar e agir hão de se deixar acompanhar sempre que quiserem vislumbrar um sentido mais amplo, sem a perda da independência que lhes é própria em suas esferas. Quando ocorre, ela é um senso bem afinado para o sentido do todo no meio da experiência da incompletude" (Idem). 


\section{Referências}

ADAMS, R. M. Faith and Religious Knowledge. In: MARIÑA, Jacqueline. (Ed.). The Cambridge Companion to Friedrich Schleiermacher. New York: Cambridge, University Press, 2005.

DREHER, L. H. Dependência e Liberdade: Schleiermacher, Schelling e os Modos da Relação com o Absoluto In: Numen: revista de estudos e pesquisa da religião, Juiz de Fora, v. 7, n. 2, 2004, p. 59-77.

. O Método Teológico de Friedrich Schleiermacher (Série Teses e Dissertações, n.6), São Leopoldo: IEPG/Editora Sinodal, 1995, onde, como apêndices, encontram-se traduzidos o "Primeiro Discurso: Apologia" das Reden über die Religion (ibid., p. 87-101).

- Subjetividade, Religiosidade e interesse filosófico: aportes perenes da obra de Friedrich D. E. Schleiermacher, In: Revista Ética e Filosofia Política, Número XIX - Volume I - Junho de 2016. Disponível em: < www.ufjf.br/eticaefilosofia $>$.

FABERO, J. M. ¿Es posible la filosofía de la religión en la época moderna a través del pensamiento de Kant y Schleiermacher? In: Daimon. Revista Internacional de Filosofía, $\mathrm{n}^{\circ} 69$, 2016, 55-72. Disponível em: < http://dx.doi.org/10.6018/daimon/218321>.

IZUZQUIZA, I. Armonía y razón: La filosofía de Fricdrich D. E. Schleiermacher. Zaragoza: Prensas Universitarias de Zaragoza, 1998.

KANT, I. A religião nos limites da simples razão. Lisboa: Edições 70, 2008.

. Crítica da razão prática. São Paulo: Martins Fontes, 2003.

MARINA, J. Schleiermacher, Realism, and Epistemic Modesty. In: Brent Sockness \& Wilhelm Gräb (eds.), Schleiermacher, the Study of Religion, and the Future of Theology. de Gruyter (2010)

OLIVEIRA, at al. O primado da experiência e a intencionalidade da consciência: Friedrich Schleiermacher e a fenomenologia da religião. In: Sacrilegens, Juiz de Fora, v.7, n.1, p.18-32, 2010. Disponível em: $<$ http://www.ufjf.br/sacrilegens/files/2011/02/7-3.pdf $>$.

OLIVEIRA, D. S. de. A consciência originária do infinito e sua manifestação na história segundo Schleiermacher, In: PLURA, Revista de Estudos de Religião, vol. 2, no 2, 2011, p. 140-165.

- Filosofia da Religião e Ciência da Religião: breves incursões em diálogo com Schleiermacher. Horizonte, Belo Horizonte, v. 14, n. 44, p. 1565-1588, 2016.

. O conceito de espiritualidade a partir de uma abordagem filosófica da subjetividade.

In: Dossiê Espiritualidade no Mundo Moderno, Revista Brasileira de Filosofia da Religião V.3 N.1, Brasília, $2016 b$.

Sentimento e autoconsciência imediata na filosofia da religião de Schleiermacher.

Dissertação (Mestrado em Ciência da Religião) - Universidade Federal de Juiz de Fora, Juiz de Fora, $2011 b$.

PANNENBERG, W. Filosofia e Teologia: tensões e convergências de uma busca comum.

São Paulo: Paulinas, 2008, p. 221.

SCHLEIERMACHER, F. D. E. Discursos a Seus Menosprezadores Eruditos, de Friedrich

Daniel Ernst Schleiermacher. Trad. Daniel Costa. São Paulo: Novo Século, 2000. 
, F. D. E. Über die Religion: Reden an die Gebildeten unter ihren Verächtern. Hamburg: Verlag von Felix Meiner, 1970. 